\title{
Aplikasi Monitoring Inventaris Sekolah di Dinas Pendidikan Kota Tidore Kepulauan
}

\author{
Bahmid Hadi, Benefit S. Narasiang, Agustinus Jacobus \\ Teknik Informatika Universitas Sam Ratulangi Manado, Indonesia. \\ bahmidhadi9@gmail.com, benefitsemuel@unsrat.ac.id, a.jacobus@unsrat.ac.id
}

\begin{abstract}
Abstrak- Komputer merupakan suatu perangkat yang sangat dibutuhkan untuk proses pengolahan data, agar data yang diolah tersebut secara efektif dan efisien dapat memberikan informasi yang diperlukan oleh suatu instansi. Pengolahan data yang dilakukan secara komputerisasi memerlukan tenaga lebih sedikit dan memerlukan waktu lebih singkat. Dinas Pendidikan Kota Tidore Kepulauan saat ini belum memiliki website yang digunakan untuk proses pengelolaan data inventaris Sekolah sehingga dapat menghambat proses pengelolaan data. Berdasarkan identifikasi masalah maka solusi untuk permasalahan tersebut dengan membuat Aplikasi Monitoring Inventaris Sekolah berbasis Web pada Dinas Pendidikan Kota Tidore Kepulauan. Aplikasi ini diharapkan dapat membantu petugas dalam mengolah data inventaris, input inventaris Sekolah, dan pemantauan pembuatan laporan inventaris Sekolah menjadi cepat dan efisien.
\end{abstract}

Kata Kunci: Aplikasi Monitoring, Dinas Pendidikan Kota Tidore Kepulauan, Website.

Abstract- A computer is a device that is needed for data processing, so that the processed data can effectively and efficiently provide information needed by an agency. Data processing carried out in a computerized manner requires less energy and takes less time. The Tidore Islands City Education Office currently does not have a website that is used for the process of managing School inventory data so that it can hamper the data management process. Based on the identification of the problem, the solution to the problem is by creating a Web-based School Inventory Monitoring Application at the Education Office of the Tidore Islands City. This application is expected to assist officers in processing inventory data, School inventory input, and monitoring of making School inventory reports to be fast and efficient.

Keywords: Monitoring Application, Education Office of Tidore Islands City, Website.

\section{PENDAHULUAN}

Seiring dengan perkembangan teknologi informasi yang sangat pesat, semakain majunya teknologi informasi sekarang ini telah menciptakan persaingan yang semakin ketat hampir di seluruh aspek kehidupan. Hal ini mengakibatkan kebutuhan sekolah akan kebudahan proses pada segala bidang kerja semakin meningkat. Sehingga hampir semua pekerjaan dapat menghemat waktu, tenaga dan biaya. Pengolahan data menjadi informasi inilah yang dapat dijadikan sebagai salah satu kelebihan dari komputer. Kemajuan tersebut mendorong munculnya inovasi baru dalam menyajikan sebuah sistem informasi untuk dapat memenuhi kebutuhan sekolah dalam hal ini yang berkaitan dengan informasi.

Saat ini masih banyak instansi pemerintahan khususnya monitoring inventaris sekolah masih menggunakan prosedur - prosedur secara manual yaitu menggunakan Microsoft word dan Microsoft excel dalam pengolahan data Sekolah yang begitu banyak. Tentunya cara ini sangat tidak efektif dan efisien mengingat jumlah data yang sangat besar, meskipun bisa pastilah dibutuhkan tenaga dan waktu yang tidak sedikit.

Begitupun di Dinas Pendidikan Pemuda dan Olahraga Kota Tidore Kepulauan, pengembangan sistem management informasi khususnya mengenai monitoring inventaris sekolah akan sangat membantu dalam melakukan proses pengolahan data inventaris sekolah. Berdasarkan uraian permasalahan diatas, maka penulis mengambil judul proposal skripsi "Aplikasi Monitoring Inventarsi Sekolah di Dinas Pendidikan Pemuda Dan Olahraga Kota Tidore Kepulauan".

\section{A. Definisi Sistem}

Sistem yang abstrak adalah susunan gagasan-gagasan atau konsepsi yang teratur yang saling bergantung. Misalnya, sistem teologi adalah susunan yang teratur dari gagasangagasan tentang Tuhan, manusia, dan lain sebagainya. Sedangkan system yang bersifat fisik adalah serangkaian unsur yang bekerja sama untuk mencapai tujuan. ${ }^{[1]}$

Sistem adalah suatu jaringan kerja dari prosedur-prosedur yang saling berhubungan, berkumpul Bersama-sama untuk melakukan kegiatan atau untuk melakukan sasaran yang tertentu. Pendekatan sistem yang merupakan jaringan kerja dari prosedur lebih menekankan urutan-urutan operasi di dalam sistem. ${ }^{[2]}$

\section{B. Konsep Dasar Informasi}

Informasi merupakan proses lebih lanjut dari data yang sudah memiliki nilai tambah. Informasi dapat dikelompokan menjadi 3 bagian, yaitu:

1) Informasi Strategis. Informasi ini digunakan untuk mengambil keputusan jangka panjang, yang mencakup 
informasi eksternal, rencana perluasan perusahaan, dan sebagainya.

2) Informasi Taktis. Informasi ini dibutuhkan untuk mengambil keputusan jangka menengah, seperti informasi tren penjualan yang dapat dimanfaatkan untuk menyusun rencan penjualan.

3) Informasi Teknis. Informasi ini dibutuhkan untuk keperluan operasional sehari-hari, seperti informasi persediaan stock, retur penjualan, dan laporan kas harian.

Istilah informasi seringkali tidak tepat pemakaianya. Informasi dapat merujuk ke suatu data mentah, data tersusun, kapasitas sebuah saluran komunikasi, dan lain sebagainya. Informasi ibarat darah yang mengalir di dalam tubuh organisasi, sehingga peran dan kedudukan informasi ini sangat penting di dalam suatu organisasi.

\section{Konsep Dasar Sistem Informasi}

Sistem informasi bukan merupakan hal yang baru. Yang baru adalah komputerisasinya. Sebelum ada komputer, teknik penyaluran informasi yang memungkinkan manajer merencanakan serta mengendalikan operasi telah ada. Komputer menambahkan satu atau dua dimensi, seperti kecepatan, ketelitian, dan penyedian data dengan volume yang lebih besar yang memberikan bahan pertimbangan yang lebih banyak untuk mengambil keputusan. Sistem informasi adalah suatu sistem di dalam suatu organisasi yang mempertemukan kebutuhan pengolahan transaksi harian yang mendukung fungsi operasi organisasi yang bersifat manajerial dengan kegiatan strategi dari suatu organisasi untuk dapat menyediakan laporan-laporan yang diperlukan oleh pihak luar tertentu. ${ }^{[8]}$

\section{Komponen Sistem Informasi}

Sistem informasi terdiri dari komponen-komponen yang disebut dengan istilah blok bangunan (building block), yang terdiri dari blok masukan, blok model, blok keluaran, blok teknologi, blok basis data, dan blok kendali. Sebagai suatu sistem, keenam blok tersebut saling berinteraksi satu dengan yang lain membentuk satu kesatuan untuk mencapai sasaran.

1) Blok masukan (input block)

Input mewakili data yang masuk ke dalam system informasi. Yang dimaksud dengan input di sini termasuk metode dan media untuk menangkap data yang akan dimasukkan, yang dapat berupa dokumen-dokumen dasar.

2) Blok model (model block)

Blok terdiri dari kombinasi prosedur, logika, dan model matematik yang akan memanipulasi data input dan data yang tersimpan di basis data dengan cara yang sudah tertentu untuk menghasilkan keluaran yang di inginkan.

3) Blok keluaran (output block)

Produk dari system informasi adalah keluaran yang merupakan informasi yang berkualitas dan dokumentasi yang berguna untuk semua tingkatan manajemen serta semua pemakai sistem.

4) Blok teknologi (teckhnology block)

Teknologi merupakan tool box dalam sistem informasi. Teknologi digunakan untuk menerima input, menjalankan model, menyimpan dan mengakses data, menghasilkan dan mengirimkan keluaran dan membantu pengendalian system secara keseluruhan.

5) Blok basis data (database block)

Basis data (database) merupakan kumpulan data yang saling berkaitan dan berhubungan dengan satu dengan lainnya, tersimpan di perangkat keras komputer dan perangkat lunak di gunakan untuk memanipulasinya. Data perlu di simpan dalam basis data untuk keperluan penyediaan informasi lebih lanjut.

6) Blok kendali (control block)

Banyak hal dapat merusak system informasi, seperti bencana alam, api, temperatur, air, debu, kecurangankecurangan, kegagalan pada system itu sendiri, ketidakefisienan, sabotase, dan lain sebagainya. ${ }^{[8]}$

\section{E. Penilaian Sistem Informasi}

Fungsi utama dari penilaian informasi adalah menyediakan informasi sebagai bahan pertimbangan untuk membuat keputusan. Siapa pun dapat membuat keputusan setelah dia memperoleh informasi yang merupakan hasil penilaian sesuai dengan tugas dan fungsinya.

Sehubungan dengan hal tersebut, maka ditentukan 3 (tiga) strategi penilaian dalam sistem informasi, yaitu sebagai berikut:

1) Strategi penilaian masukan yang bertujuan menilai perencanaan informasi yang di susun berdasarkan kebutuhan informasi yang nyata.

2) Startegi penilaian proses yang bertujuan menilai pelaksanaan transformasi informasi, mulai dari pengumpulan data, pengolahan, analisis dan penilaian, penyajian dan penyebarluasan, dokumentasi, dan komunikasi yang secara keseluruhan merupakan suatu proses yang berkesinambungan.

3) Strategi penilaian produk, yang bertujuan untuk menilai produk-produk informasi yang dihasilkan oleh system informasi.

Dengan demikian, benar bahwa penilaian menjadi satu bagian yang penting dalam pengelolaan system informasi, tidak disamkan dengan pemberian angka terhadap hasil kegiatan di bidang informasi. Penilaian mengandung makna yang sangat luas dan sangat penting dalam keseluruhan pengelolaan sistem informasi.

Berdasarkan hasil penilaian dapat di buat keputusan yang tepat dan objektif tentang berbagai kegiatan pengelolaan sistem informasi, seperti:

1) Derajat keakuratan informasi yang di peroleh berdasarkan kebutuhn lapangan secara nyata.

2) Perencanaan informasi yang bermutu, memenuhi persyaratan yang di tetapkan bagi suatu perencanaan informasi yang baik.

3) Pelaksanaan kegiatan transformasi data dan informai berdarkan prosedur yang tepat dan benar.

4) Jenis dan mutu produk informasi yang dihasilkan oleh sistem informasi. ${ }^{[8]}$

\section{F. Basis Data}

Basis data merupakan suatu kumpulan data terhubung yang disimpan secara bersama-sama pada satu media, yang di organisasikan berdasarkan sebuah skema atau struktur tertentu, dengan software untuk melakukan manipulasi untuk 
kegunaan tertentu. Basis data bisa diartikan juga sebagai sekumpulan data yang disusun dalam bentuk beberapa tabel yang saling memiliki relasi maupun berdiri sendiri. ${ }^{[7]}$

Basis data adalah suatu pengorganisasian sekumpulan data yang saling terkait sehingga memudahkan aktivitas untuk memperoleh informasi. Sejauh ini basis data tidak hanya berguna pada tataran perusahan, melainkan juga keperluan pribadi. Dengan menggunakan perangkat lunak basis data seperti Microsoft Access, seseorang dapat mengelola data yang menjadi urusan pribadi, seperti data telepon dan data belanja bulanan, dan jika diperlukan segala informasi dapat diperoleh dengan mudah dan cepat. ${ }^{[4]}$

Database atau basis data adalah koleksi dari data-data yang terorganisasi dengan cara sedemikian rupa sehingga mudah dalam disimpan dan dimanipulasi (diperbaharui, dicari, diolah dengan perhitungan-perhitungan tertentu, serta dihapus). ${ }^{[6]}$

\section{G. Monitoring}

Monitoring adalah proses pengumpulan dan analisis informasi berdasarkan indikator yang ditetapkan secara sistematis dan kontinu tentang kegiatan/ program sehingga dapat dilakukan tindakan koreksi untuk penyempurnaan program/kegiatan itu selanjutnya. Monitoring adalah pemantauan yang dapat dijelaskan sebagai kesadaran (awareness) tentang apa yang ingin diketahui, pemantauan berkadar tingkat tinggi dilakukan agar dapat membuat pengukuran melalui waktu yang menunjukkan pergerakan kearah tujuan atau menjauh dari itu. Monitoring akan memberikan informasi tentang status dan kecenderungan bahwa pengukuran dan evaluasi yang diselesaikan berulang dari waktu ke waktu, pemantauan umumnya dilakukanuntuk tujuan tertentu, untuk memeriksa terhadap proses berikut objek atau untuk mengevaluasi kondisi atau kemajuan menuju tujuan hasil manajemen atas efek tindakan dari beberapa jenis antara lain tindakan untu mempertahankan manajemen yang sedang berjalan. ${ }^{[9]}$

\section{H. Inventarisasi}

Inventarisasi merupakan kegiatan mencatat barang yang sudah dibeli. Mencatat barang bertujuan untuk memberikan informasi. Inventarisasi adalah pencatatan dan penyusunan daftar barang milik negara secara sistematis, tertib, dan teratur berdasarkan ketentuan-ketentuan atau pedoman-pedoman yang berlaku. Inventarisasi barang yang dilakukan dengan baik dan benar memberikan tujuan yang secara tidak langsung mempengaruhi proses tercapainya suatu tujuan organisasi. Tujuan inventarisasi selain untuk mengetahui kekayaan suatu instansi juga menjaga pengamanan dan penghematan barang, tujuan inventarisasi berperan penting terhadap perencanaan pengadaan perlengkapan kebutuhan. ${ }^{[3]}$

Inventarisasi merupakan kegiatan untuk menyediakan data atas semua logistik yang dimiliki/dikuasai/diurus organisasi, baik sebagai hasil usaha pembuatan sendiri, pembelian, pertukaran, hadiah, maupun hibah, baik berkaitan dengan jenis dan spesifikasinya, jumlah, sumber, waktu pengadaan, harga, tempat, dan kondisi, serta perubahan-perubahan yang terjadi guna mendukung proses pengendalian dan pengawasan logistik, serta mendukung efektivitas dan efisiensi dalam upaya pencapaian tujuan organisasi. ${ }^{[5]}$

\section{METODOLOGI PENELITIAN}

\section{A. Metode Pengembangan Sistem}

Metode pengembangan sistem adalah metode-metode, prosedur-prosedur, konsep-konsep pekerjaan aturan-aturan yang akan digunakan untuk mengembangkan suatu sistem informasi. Selain itu RAD bertujuan untuk mempersingkat waktu pengerjaan aplikasi serta proses yang dihasilkan dapat secara tepat.

1) Tahap Scope Definition

Pada tahap ini, peneliti mendifinisikan lingkup sistem, yang artinya menentukan batas-batas pengembangan system. Tahapan ini juga menggambarkan dengan jelas dan singkat masalah kesempatan perintah yang memicu pengembangan aplikasi.

2) Analisis Sistem

Pada tahap ini, peneliti menjabarkan tentang analisis sistem yakni yakni analisis masalah, analisis persyaratan dan analisis keputusan.

3) Tahap Perancangan Sistem

Database dalam aplikasi ini dirancang menggunankan Unified Modeling Language (UML) sebagai tools dalam pengembangan aplikasi. Pada tahapan ini juga peneliti hanya menggunakan beberapa diagram yang digunakan, yang dapat mendukung perancangan aplikasi ini. antara lain:

a. Use Case Diagram, merupakan diagram yang menjelaskan aktivitas apa saja yang dilakukan sistem dan siapa saja yang berinteraksi dengan sistem

b. Class Diagram, diagram yang menunjukkan antara class dalam sistem yang sedang dibangun dan bagaimana mereka saling berkolaborasi untuk mencapai suatu tujuan

c. Activity Diagram, menggambarkan berbagai alur aktivitas dalam sistem yang dirancang, bagaimana masing-masing alur berawal sampai berakhir.

\section{4) Tahap Implementasi}

Tahap ini dilakukan pengujian terhadap sistem. Untuk uji aplikasi dilakukan dengan menggunakan metode black box yaitu suatu pengujian yang berfokus pada persyaratan fungsional perangkat lunak.

Setelah melakukan analisa sistem dan perancangan sistem secara rinci, maka tiba saatnya sistem untuk diimplementasikan. Tahap ini terdapat banyak aktivitas yang dilakukan. Aktivitas-aktivitas yang dimaksud berupa:

a. Pemprograman

Pada tahap ini hasil desain dimasukkan ke dalam bentuk bahasa pemrograman yang digunakan agar dapat dijalankan dalam bentuk aplikasi.

\section{b. Pengujian}

Pada tahap ini dilakukan uji coba terhadap sistem yang baru agar dapat digunakan tanpa menemukan kendalakendala apapun. 


\begin{tabular}{|c|c|}
\hline Pengguna & Tugas dan Tanggung Jawab \\
\hline Admin & $\begin{array}{l}\text { 1. Memantau laporan Inventaris Sekolah } \\
\text { 2. Melihat Data User serta dapat } \\
\text { menghapus Sekolah sebagai User } \\
\text { 3. Melakukan registrasi Sekolah agar } \\
\text { terdaftar sebagai User } \\
\text { 4. Melihat dokumentasi kegiatan sekolah } \\
\text { dalam menu Galeri }\end{array}$ \\
\hline User & $\begin{array}{l}\text { 1. Menginput Laporan Inventaris } \\
\text { 2. Mengupload dokumentasi kegiatan } \\
\text { sekolah } \\
\text { 3. Mendapaatkan username dan password } \\
\text { dari petugas } \\
\text { 4. Login untuk bisa masuk sebagai } \text { user }\end{array}$ \\
\hline
\end{tabular}

\section{B. Analisa Modeling}

Bertujuan menganalisis semua kegiatan dalam arsitektur sistem secara keseluruhan dengan cara mengidentifikasi dan abstraksi sistem yang mendasar.

Tabel I. Penjelasan pengguna dan tanggung jawabnya, admin dapat mengelola database dengan membuat, menambah, mengedit, atau menghapus database yang ada pada server (Pembuat) sedangkan user melihat data yang nantinya akan disimpan ke dalam web atau informasi yang ada serta bertindak sebagai pengguna aplikasi Monitoring Inventaris Sekolah pada Dinas Pendidikan Kota Tidore Kepulauan.

\section{HASIL DAN PEMBAHASAN}

\section{A. Perancangan Sistem}

Gambar 1 Use Case Diagram yang menjelaskan sebuah interaksi antara User/Sekolah dan Admin pada Aplikasi Monitoring Inventaris Sekolah di Dinas Pendidikan Kota Tidore Kepulauan.

Gambar 2 Class Diagram pada penilitan ini memiliki sebelas kelas yaitu Class penata petugas, class sekolah, class pengadaan, class suplier, class galeri, class peralatan mesin, class gedung bangunan, class hewan ternak tumbuhan, kesenian kebudayaan, class buku perpustakaan dan class aset tetap lain. Sedangakn id pada class sekolah berhubungan dengan Id pada class pengadaan, supplier, galeri, peralatan mesin, gedung bangunan, hewan ternak tumbuhan, kesenian kebudayaan, buku perpustakaan dan Id class aset tetap lain. Sedangkan Class Penata Petugas bertugas menambahkan Sekolah sebagai User dan juga bertugas melakukan monitoring pada Sekolah sudah melakukan proses penginputan laporan Inventaris.

Gambar 3 Activity Diagram menggambarkan alur-alur kerja atau aktivitas dalam system yang sedang dirancang, bagaimana masing-masing alur berjalan, pada Aplikasi Monitoring Inventaris Sekolah dan bagaimana berakhir.

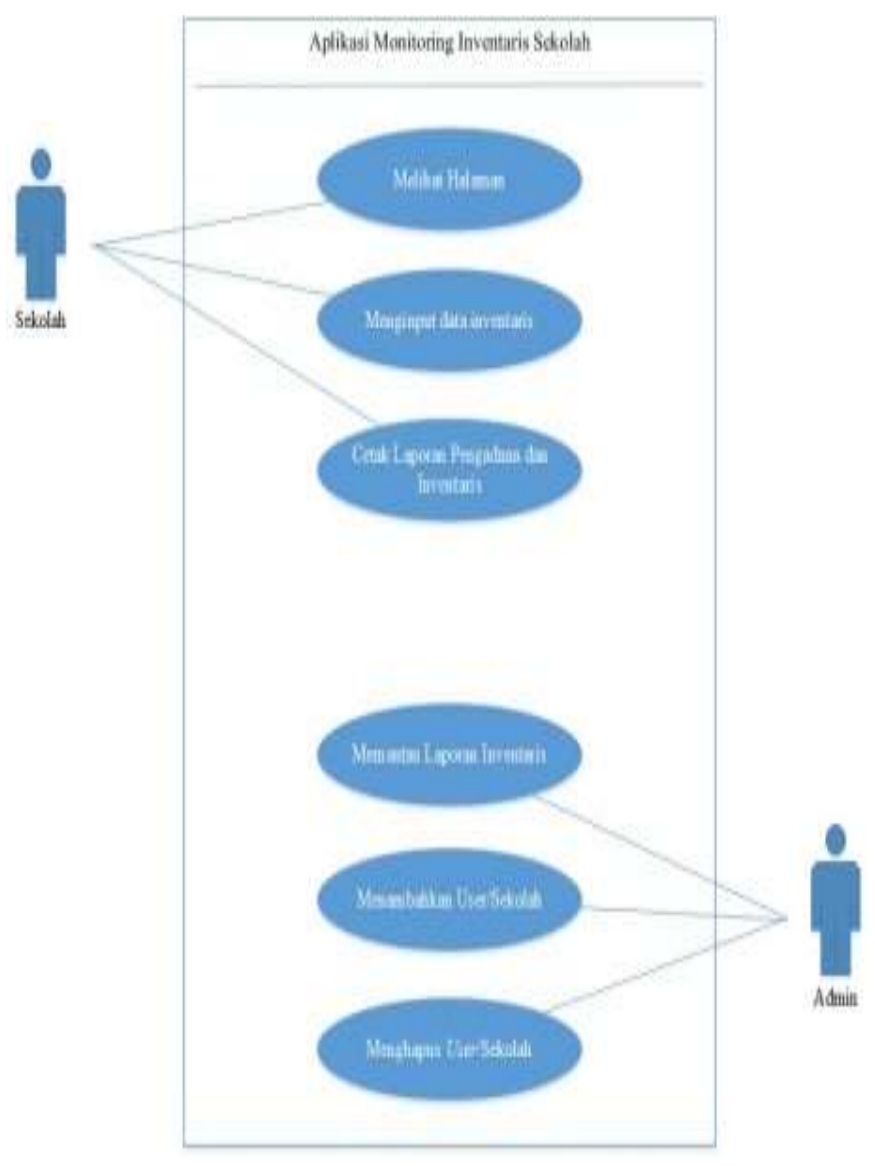

Gambar 1 Use Case Diagram

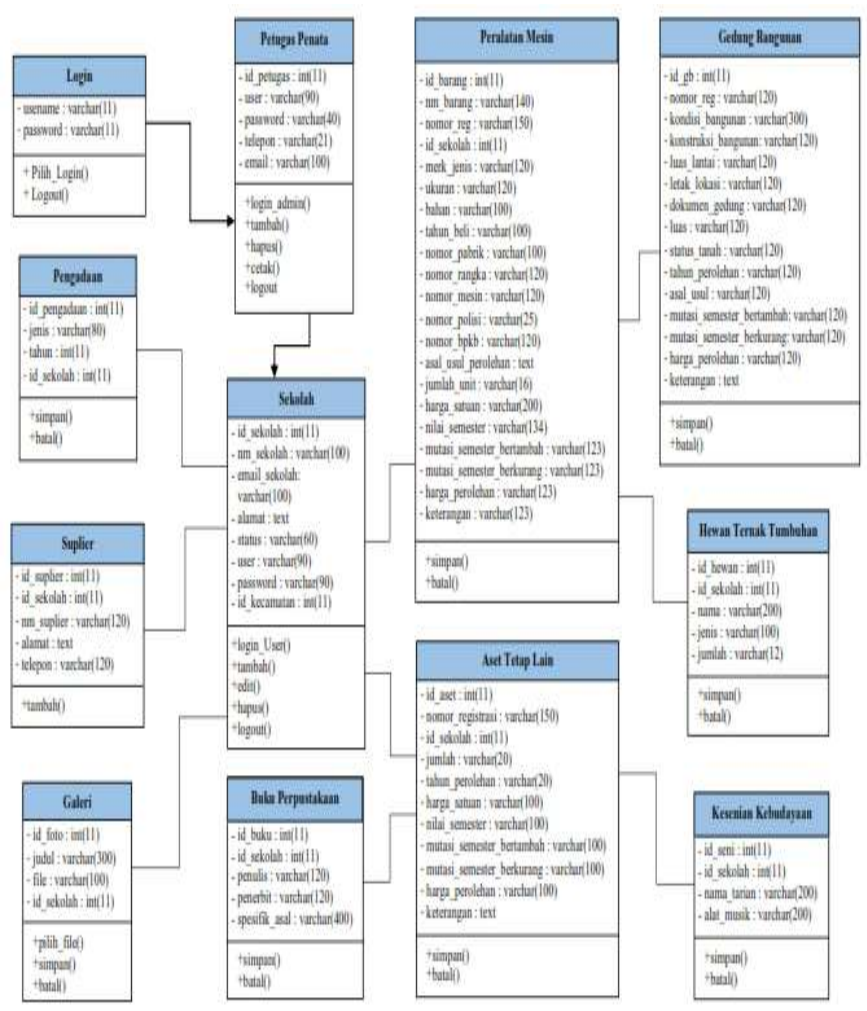

Gambar 2 Class Diagram 


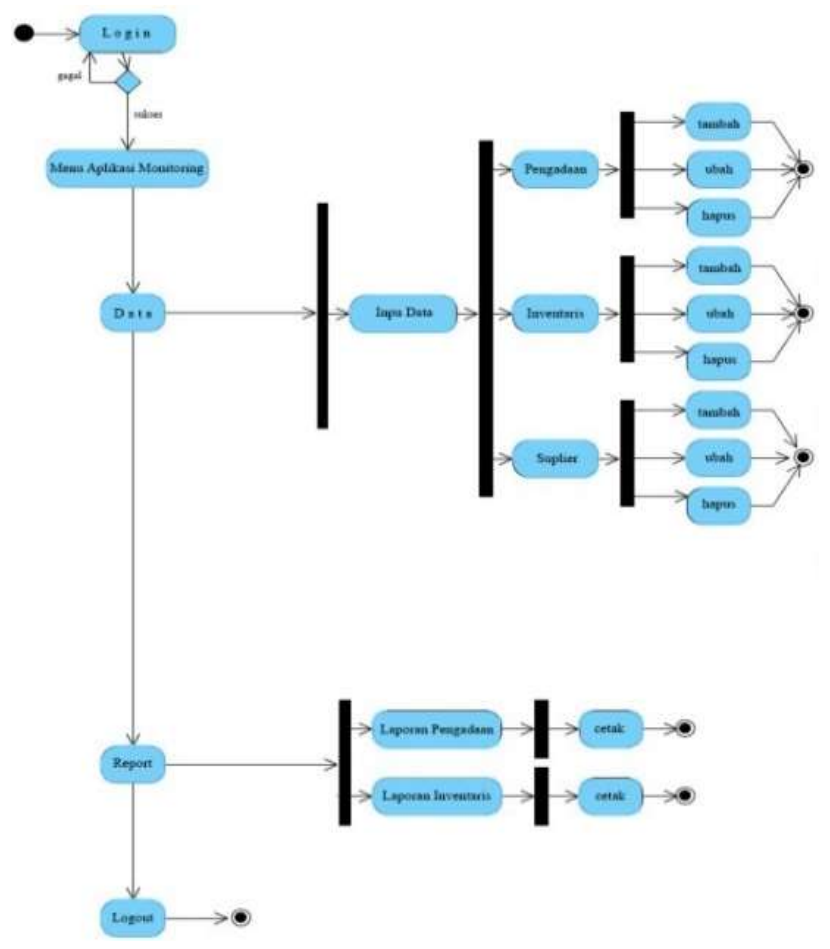

Gambar 3 Activity Diagram

\section{B. Implementasi Antarmuka Aplikasi Monitoring Inventaris} Sekolah

Pada tahap selanjutnya adalah tahap merancang tampilan antarmuka untuk aplikasi yang akan dibangun, tampilan antarmuka ini bersifat sementara atau merupakan acuan sementara, untuk kedepannya saat implementasi tampilan antarmuka ini bisa saja terjadi perubahan sesuai dengan kubutuhan pada Dinas Pendidikan Kota Tidore Kepulauan. Tampilan antarmuka aplikasi ini dapat dilihat dari komponenkomponen penyusun tampilan antarmuka dan keterangan antarmuka pada kondisi tertentu yang akan di bangun. Agar lebih jelas dapat dilihat pada gambar-gambar tampilan antarmuka dibawah ini.

Aplikasi Monitoring Inventaris Sekolah di Dinas Pendidikan Kota Tidore Kepulauan mempunyai tampilan antarmuka antara lain, yaitu:

Gambar 4 halaman login ini berfungsi untuk memasukan username dan password agar dapat membuka aplikasi Monitoring Inventaris Sekolah, pada halaman login ini juga terdapat pilihan apabila admin yang membuka aplikasi maka harus pilih admin agar bisa login sebagai admin dan sebaliknya juga kalau login pilih user/sekolah.

Gambar 5 halaman home merupakan tampilan utama setelah melakukan proses login untuk bisa masuk ke Aplikasi Monitoring Inventaris Sekolah di Dinas Pendidikan Kota Tidore Kepulauan, apabila pada pilihan login dengan memilih admin, maka pada halaman home tertulis selamat datang, anda login sebagai admin. Dan sebaliknya login dengan memilih user/sekolah, maka yang muncul pada halaman home adalah kalimat selamat dating, anda login sebagi user.
Gambar 6 halaman user ini hanya dapat di lihat oleh admin, halaman ini hanya dapat di akses oleh admin untuk melihat semua data user yang sudah di registrasi sebagai user oleh admin, admin dapat menghapus user/sekolah dari aplikasi melalui halaman user kemudian klik hapus.

Gambar 7 halaman supplier ini menjelaskan tentang fungsi dan kegunaan dari aplikasi pada halaman supplier, pada halaman supplier ini admin maupun user dapat mengaksesnya, karena pada halaman ini admin maupun user menambahkan data supplier baik dari Diknas maupun Sekolah.

Gambar 8 halaman laporan ini terdapat dua sub menu, yaitu menu laporan pengadaan yang berfungsi untuk melihat laporan pengadaan sekaligus dapat mencetak laporan dengan mengklik cetak pdf atau bisa klik import excel dan menu laporan inventaris klik pilih jenis inventaris yang akan di cetak. Pada halaman ini admin dan user/sekolah dapat mengaksesnya.

Gambar 9 halaman registrasi sekolah yang menjelaskan tentang bagaimana petugas atau pegawai pada Dinas Pendidikan Kota Tidore Kepulauan kemudian melakukan proses registrasi sekolah melalui aplikasi Monitoring Inventaris Sekolah atau menambahkan sekolah sebagai user, setelah itu sekolah akan mendapatkan username dan password dari petugas untuk bisa membuka aplikasi. Halaman ini hanya dapat di akses oleh admin.

Gambar 10 halaman inventaris merupakan halaman yang berfungsi untuk melakukan proses penginputan data, halaman ini hanya dapat di akses oleh user/sekolah untuk input data inventaris sekolah. Adapun form input pada halaman inventaris yaitu form peralatan mesin, Gedung bangunan, buku perpustakaan, hewan ternak tumbuhan, kesenian kebudayaan dan aset tetap.

Gambar 11 halaman pengadaan ini menjelaskan tentang fungsi dari pada halaman pengadaan di aplikasi. Halaman pengadaan hanya dapat di akses oleh user/sekolah, karena pada halaman ini user melakukan proses penginputan data pengadaan barang maupun inventaris sekolah.

Gambar 12 Galeri merupakan halaman yang di akses oleh user/sekolah untuk mengupload foto atau dokumentasi kegiatan - kegiatan yang di laksanakan oleh sekolah selama satu semester berjalan, agar petugas dari Dinas Pendidikan Pemuda dan Olahraga Kota Tidore Kepulauan dengan mudah dapat memantau setiap kegiatan yang dilakukan, karena pada halaman galeri admin hanya dapat melihat foto tetapi tidak dapat mengupload foto.

Gambar 13 halaman about ini hanya berisi kata sambutan dari Kepala Dinas Pendidikan Pemuda dan Olahraga Kota Tidore Kepulauan, sambutan yang berkaitan dengan manfaat dan kegunaan dari Aplikasi Monitoring Inventaris Sekolah di Dinas Pendidikan Kota Tidore Kepulauan. Halaman ini dapat oleh admin maupun user/sekolah. 


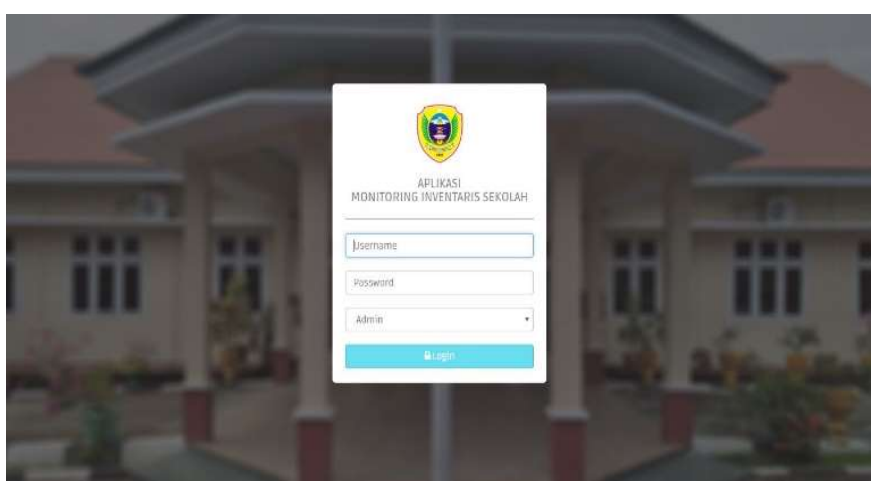

Gambar 4 Halaman Login

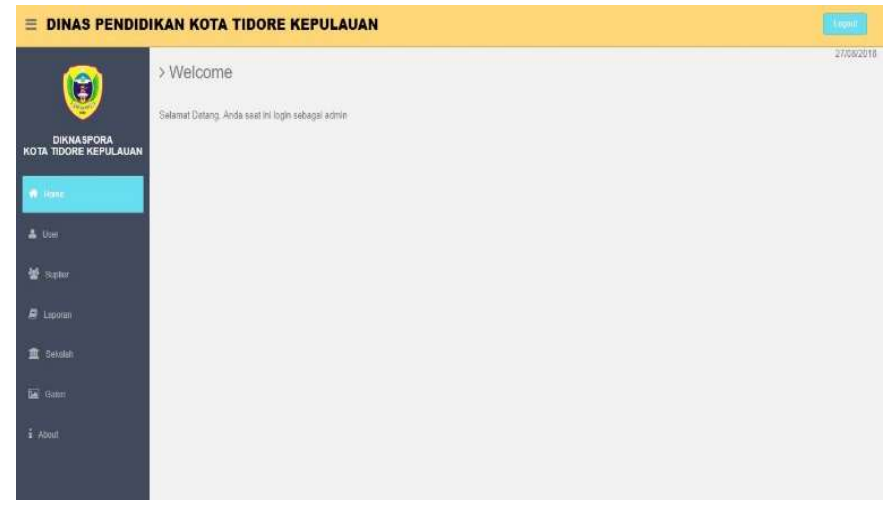

Gambar 5 Halaman Home

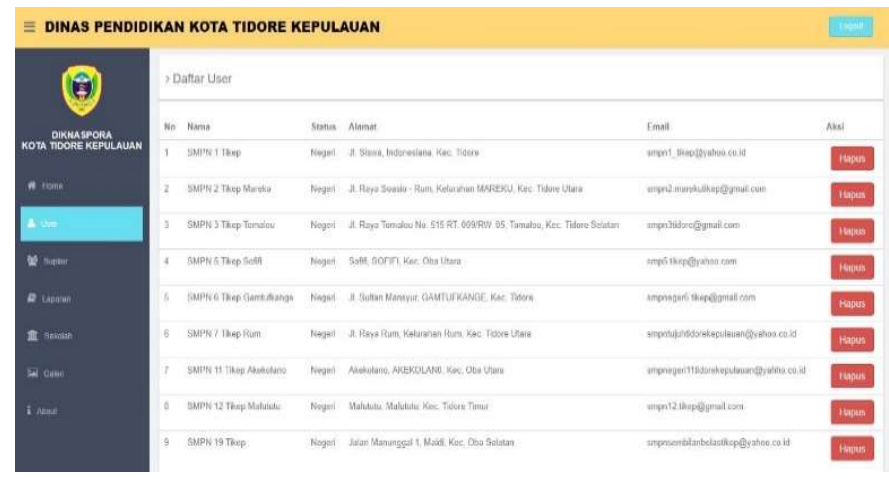

Gambar 6 Halaman User

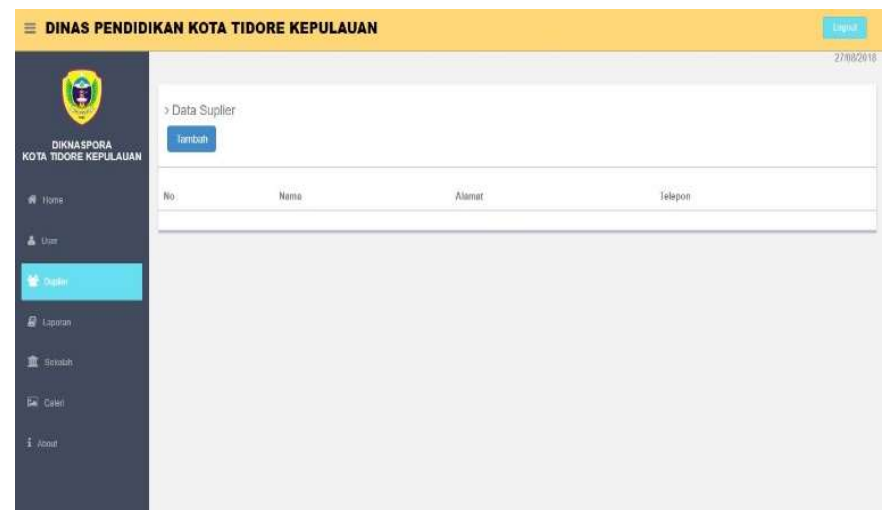

Gambar 7 Halaman Suplier

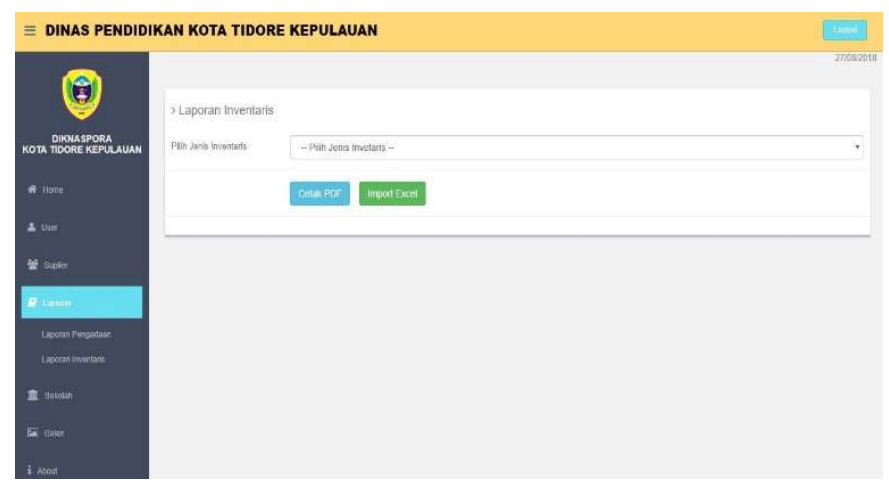

Gambar 8 Halaman Laporan

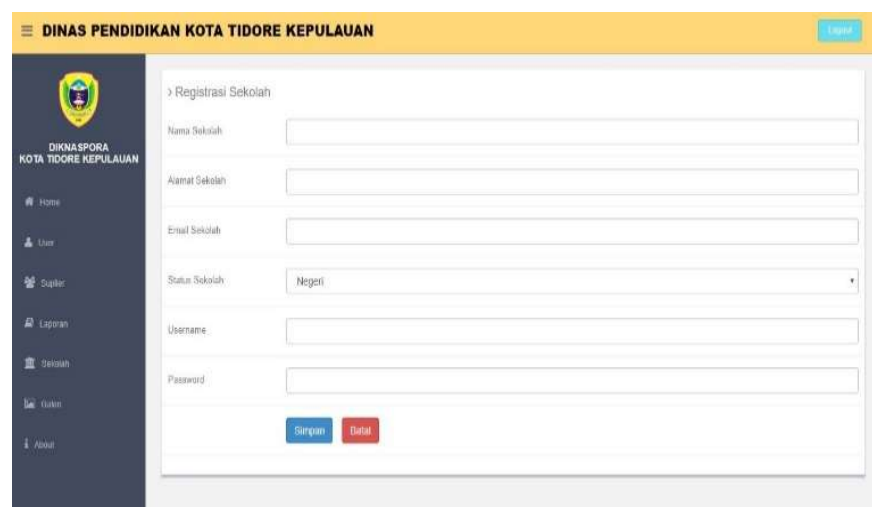

Gambar 9 Halaman Registrasi Sekolah

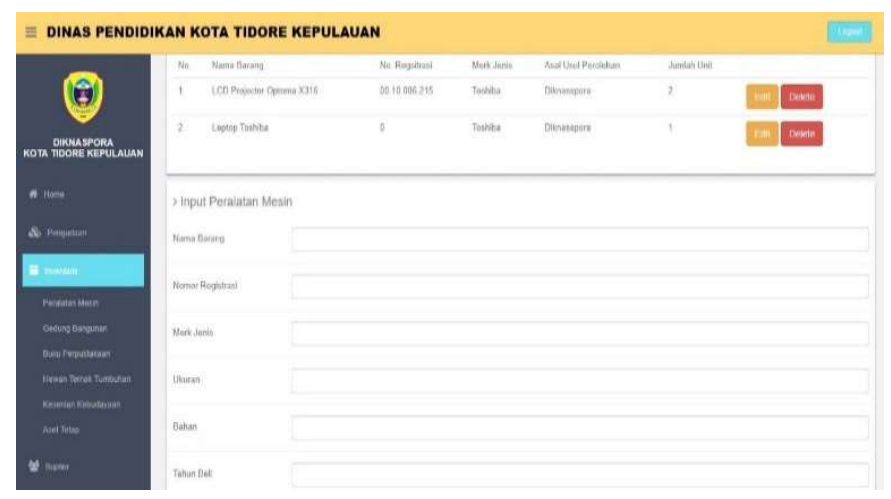

Gambar 10 Halaman Inventaris

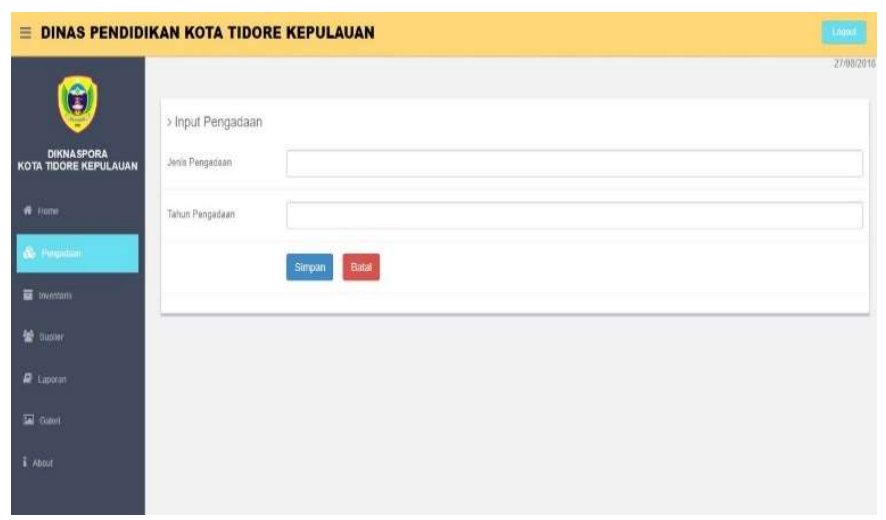

Gambar 11 Halaman pengadaan 
TABEL II. PENGUJIAN BLACK BOX

\begin{tabular}{|l|c|c|c|c|}
\hline $\begin{array}{l}\text { Kasus/For } \\
\text { m Uji }\end{array}$ & $\begin{array}{c}\text { Tes } \\
\text { Case }\end{array}$ & $\begin{array}{c}\text { Hasil yang di } \\
\text { harapkan }\end{array}$ & $\begin{array}{c}\text { Hasil } \\
\text { Penguji } \\
\text { an }\end{array}$ & $\begin{array}{c}\text { Kesimpu } \\
\text { lan }\end{array}$ \\
\hline
\end{tabular}

Mengosong

kan usename

dan password admin lalu klik tombol login.
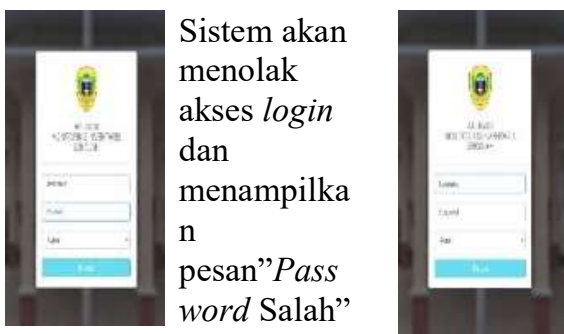

Valid

Tidak mengisi salah satu field baik username maupun password.

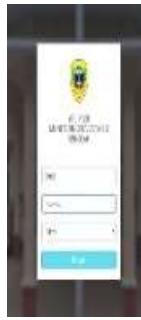

Sistem akan menampilka n pesan "field username dan password harus di isi"
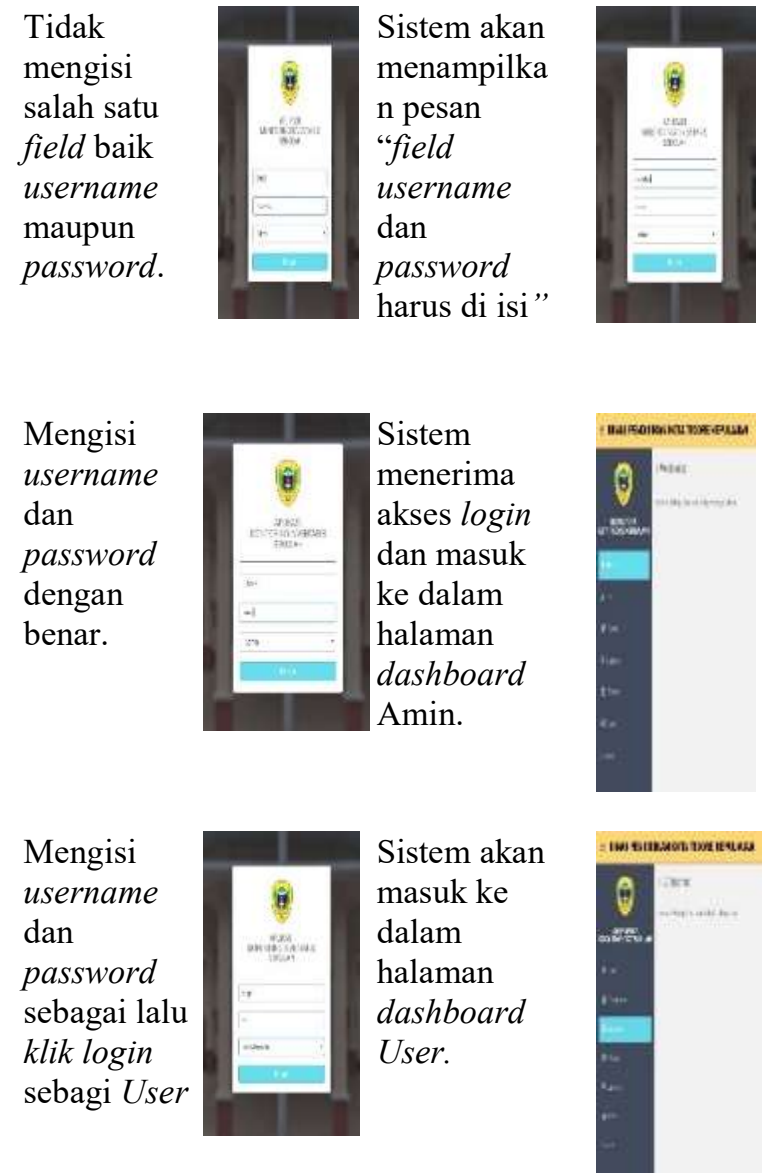

Valid

Valid

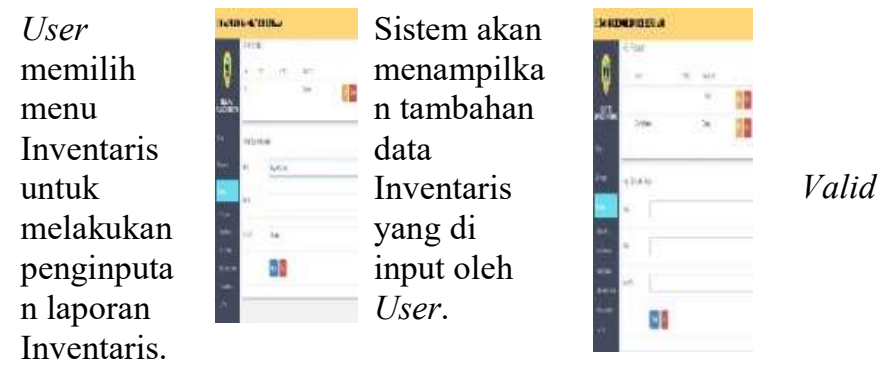

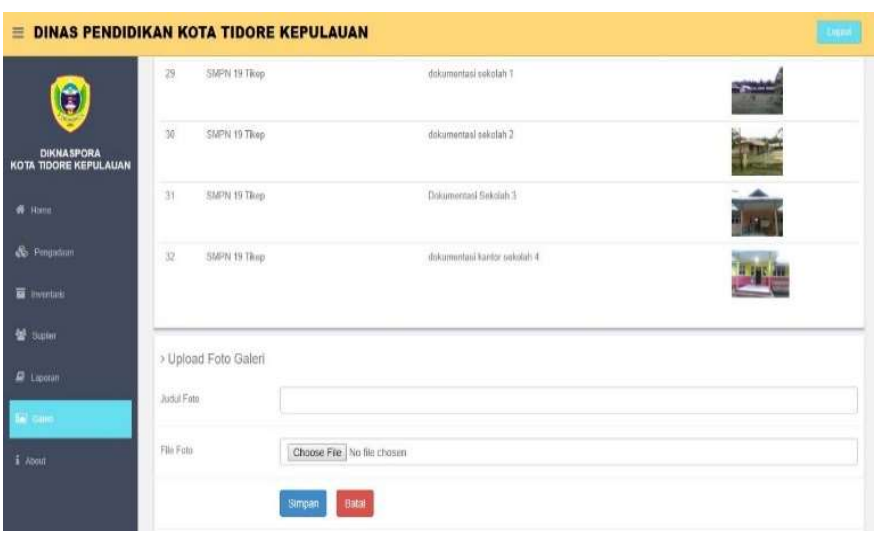

Gambar 12 Halaman Galeri

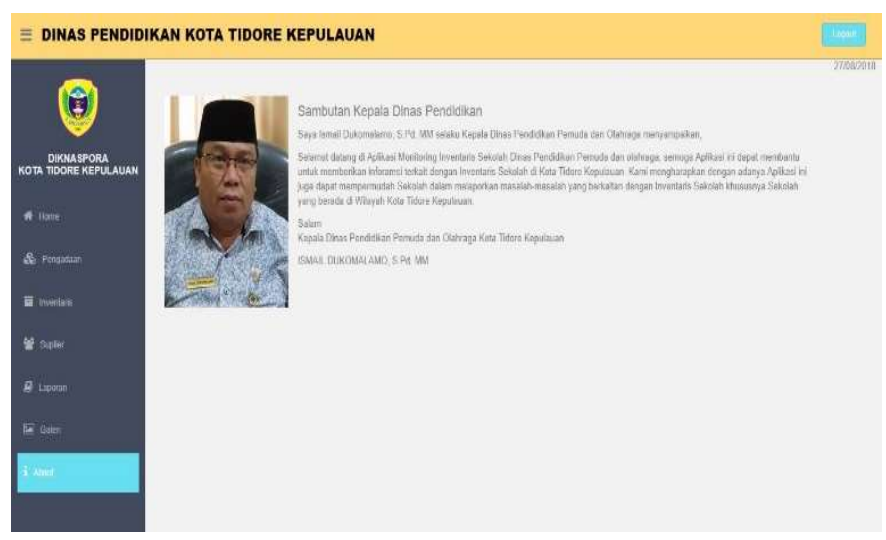

Gambar 13 Halaman About

\section{PENUTUP}

\section{A. Kesimpulan}

Kesimpulan dari akhir pembuatan aplikasi Monitoring Inventaris Sekolah yang berbasis web ini adalah sebagai betikut:

1) Aplikasi Monitoring Inventaris ini dapat membantu petugas dalam pencatatan, pengolahan dan pelaporan inventaris Sekolah.

2) Dengan adanya Aplikasi Monitoring Inventaris Sekolah ini pembuatan laporan bisa dilakukan dengan cepat dan tepat.

\section{B. Saran} berikut:

Saran-saran yang sebaiknya dilakukan yaitu sebagai

1) Aplikasi Monitoring Inventaris Sekolah ini perlu disosialisasikan kepada Sekolah-Sekolah yang berada di Wilayah Kota Tidore Kepulauan.

2) Pengembangan Aplikasi Monitoring Inventaris Sekolah yang telah di buat perlu di lakukan agar menjadi lebih baik.

3) Apabila kedepan ada yang mengembangkan aplikasi ini agar bisa menambahkan lebih banyak lagi fitur-fitur yang bagus dan menarik. 


\section{KUTIPAN}

[1] Davis B. Gordon. 1985. Management Information System: Conceptual Foundation, Structure, and Development, McGraw-Hill

[2] Hutahaean Jeperson. 2014 : Konsep Sistem Informasi. Yogyakarta. Deepublish

[3] Ibrahim Bafadal. 2004 : Manajemen Perlengkapan Sekolah. Jakarta.Bumi Aksara

[4] Kadir Abdul, Triwahyuni Ch. Terra. 2003 : Pengenalan Teknologi Informasi. Yogyakarta, Andi Offset

[5] Lukas Dwiantara, Rumsari Hadi Sumarto. 2009 : Manajemen Logistik Pedoman Praktis Bagi Sekretaris dan Staf Administrasi. Jakarta: Grasindo.

[6] 6. Nugroho, Adi. 2004 :Konsep Pengembangan System Basis Data, Bandung. Informatika Bandung

[7] Pamungkas Ajika Canggih. 2017 : Pengantar dan Implementasi Basis Data. Yogyakarta. Deepublish

[8] Sutabri Tata. 2012 : Analisis Sistem Informasi, Yogyakarta, Andi Offset

[9] Widiastuti Indriani Nelly, Susanto Rani. Kajian Sistem Monitoring Dokumen Akreditasi Teknik Informatika UNIKOM. Majalah Ilmiah UNIKOM.Vol.12 No. 2.

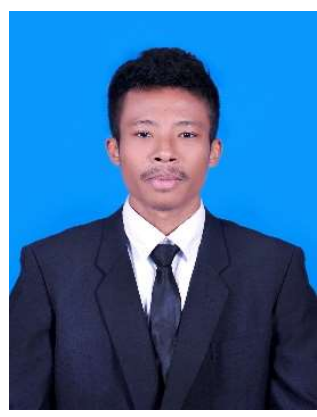

Penulis bernama Bahmid Hadi lahir di Desa Marekofo, Kecamatan Tidore Selatan, Kota Tidore Kepulauan pada tanggal 05 bulan April tahun 1992 dan merupakan anak ke lima dari pasangan Hadi Laha dan Rabiha Nuru.

Penulis mulai menempuh Pendidikan formal pertama di Sekolah Dasar SDN Marekofo tahun 1999 dan lulus pada tahun 2005. Kemudian, penulis menempuh Pendidikan pada Sekolah Menengah Pertama di SMP Muhamadiyah 1 Kota Tidore Kepulauan tahun 2005 dan lulus 2008. Selanjutnya, penulis melanjutkan menempuh Pendidikan ke Sekolah Menengah Kejuruan SMK Negeri 1 Kota Tidore Kepulauan, Provinsi Maluku Utara tahun 2008 dan lulus pada tahun 2011.

Pada tahun 2011, setelah lulus dari SMK Negeri 1 Kota Tidore Kepulauan, penulis melanjutkan Pendidikan ke jenjang Perguruan Tinggi di Universitas Sam Ratulangi Manado, Fakultas Teknik, Jurusan Teknik Elektro, Program Studi Teknik Informatika. Selama masa kuliah penulis menjalani aktivitas luar Kampus dengan mengikuti Organisasi Ekstra di Pergerakan Mahasiswa Islam Indonesia (PMII) Cabang Manado dan Organisasi Paguyuban yang di kenal dengan nama Forum Mahasiswa Kota Tidore Kepulauan (FOMAKATI) - Manado.

Pada bulan Agustus 2018, Alhamdulillah penulis dinyatakan lulus melalui Sidang Sarjana Program Studi Teknik Informatika, Universitas Sam Ratulangi dengan menyandang Gelar Sarjana Komputer (S.Kom). 